\title{
Risco sanitário do mel no Brasil em relação a novas ameaças: resíduos e contaminantes químicos emergentes
}

\author{
Honey health risk in Brazil related to new threats: emerging \\ chemical residues and contaminants
}

\section{Thiago Bousquet Bandinil,* \\ Bernardete Ferraz Spisso"}

I Instituto de Tecnologia em Fármacos, Fundação Oswaldo Cruz (Far-Manguinhos/Fiocruz), Rio de Janeiro, RJ, Brasil

" Instituto Nacional de Controle de Qualidade em Saúde, Fundação Oswaldo Cruz (INCQS/Fiocruz), Rio de Janeiro, RJ, Brasil

\footnotetext{
* E-mail: thiago.farmanguinhos@ gmail.com
}

Recebido: 31 mai 2016

Aprovado: 6 fev 2017

\begin{abstract}
RESUMO
Esta revisão de literatura narrativa trata do mel, sua contextualização como produto de variadas utilizações e com significativa relevância socioeconômica, tendo como objetivo descrever alguns resíduos e contaminantes químicos emergentes e seus aspectos relacionados à Vigilância Sanitária. 0 mel é uma substância que, além de ser utilizada como alimento desde o início da civilização humana, possui aplicações terapêuticas e farmacotécnicas. O Brasil está entre os grandes produtores e exportadores mundiais de mel, cuja produção tem relevante papel socioeconômico no país. Como outros produtos de origem animal, o mel está sujeito à presença de resíduos de substâncias utilizadas na proteção dos enxames e de contaminantes provenientes do meio ambiente. Apesar da presença de substâncias no mel com potencial impacto na saúde ser esperada pelas agências sanitárias, é necessária a atualização quanto a quais substâncias devem ou não ser monitoradas. Essa revisão relaciona exemplos de classes de substâncias que atualmente não são monitoradas, tidas como "emergentes" por ainda não serem regulamentadas adequadamente no Brasil e em diversas partes do mundo. Para os contaminantes emergentes aqui tratados, publicações científicas com dados nacionais são escassas ou inexistentes quando se trata de mel, demostrando que há necessidade de produção de conhecimento científico nessa área. Recomenda-se mais estudos acerca da ocorrência de quinolonas, alcaloides pirrolizidínicos, graianotoxinas e de substâncias utilizadas na produção de polímeros em mel no Brasil, para que riscos sanitários provenientes do consumo de mel contendo essas substâncias possam ser conhecidos e minimizados ou eliminados.
\end{abstract}

PALAVRAS-CHAVE: Mel; Resíduos; Contaminantes; Fitotoxinas; Quinolonas; Vigilância Sanitária

\begin{abstract}
This narrative literature review deals with the honey, its context as a product of varied uses and with significant socio-economic relevance, aiming to describe some emerging chemical residues and contaminants and their aspects related to Health Surveillance. Honey is a substance that, beyond being used as food since the beginning of human civilization, also has therapeutic and pharmacothecnical applications. Brazil is among the major world producers and exporters of honey and this production play a relevant socio-economic role in the country. Like other products of animal origin, honey is subject to the presence of residues of substances used in the protection of swarms and contaminants from the environment. Despite the presence of substances in honey with potential impact on health is expected by health agencies, it is required to update as to which substances should or should not be monitored. This review lists examples of classes of substances that are not currently monitored, considered as "emerging" for not being regulated properly in Brazil and in many parts of the world. For the emerging contaminants covered here, scientific publications with national data are scarce or non-existent when it comes to honey, showing that new scientific knowledge production is needed in this area. It is recommended further study of the occurrence of quinolones, pyrrolizidine alkaloids, grayanotoxins and substances used in the production of polymers in honey in Brazil, so that health risks from the consumption of honey containing these substances are known and minimized or eliminated.
\end{abstract}

KEYWORDS: Honey; Residues; Contaminants; Fitotoxins; Quinolones; Sanitary Surveillance 


\section{INTRODUÇ̃̃O}

Este trabalho aborda, na forma de uma revisão de literatura narrativa, alguns resíduos e contaminantes químicos emergentes em mel.

O texto traz definições a respeito do mel, trata de suas utilizações em diferentes áreas e apresenta sua relevância socioeconômica para contextualizar sua situação no Brasil. Em seguida, são apresentados os conceitos de resíduos e contaminantes aplicados à produção de mel e são destacados resíduos e contaminantes emergentes considerados de extrema relevância pelos autores, dada a comparação do estado da arte atualmente encontrada no país e no exterior. $O$ objetivo deste trabalho é analisar os cenários de Vigilância Sanitária (VISA) para o mel dentro e fora do país, retratando a situação atual deste produto de origem animal em relação a tais contaminantes emergentes.

\section{MÉTODO}

Revisões de literatura narrativas são publicações amplas utilizadas para descrever e discutir o desenvolvimento ou o "estado da arte" de um determinado assunto, sob ponto de vista teórico ou contextual, tendo papel fundamental para a educação continuada'.

Por se tratar de uma revisão de literatura narrativa, os autores reuniram referências bibliográficas diversas, desde legislações até artigos científicos com o objetivo de fundamentar a relevância do produto mel, bem como das questões de VISA envolvidas na presença de resíduos e contaminantes.

As referências utilizadas neste trabalho foram selecionadas não de forma sistemática, mas de forma que fosse possível traçar um panorama geral sobre os assuntos abordados ao longo do texto, com foco nos resíduos e contaminantes discutidos. Tais referências foram localizadas nas bases de dados científicos como Science Direct, Scopus, Web of Knowledge, SciELO,dentre outras, através de pesquisas utilizando as palavras-chave honey (mel) e contaminants (contaminantes). A partir dos resultados obtidos, foram avaliados artigos que tratavam de contaminantes não previstos ou pouco discutidos em legislações ou códigos nacionais e internacionais. As demais referências (legislações, códigos, normas, metodologias analíticas, demais artigos científicos) foram buscadas de maneira direcionada para complementar a discussão, sempre que necessário. A busca por referências foi realizada continuamente entre fevereiro de 2014 e fevereiro de 2017, sendo que não houve limitação de data de publicação para seleção das referências.

\section{DEFINIÇÕES E UTILIZAÇÕES DO MEL}

Existem várias definições para o mel, muitas delas complementares umas às outras, sendo interessante destacar algumas delas. O mel alimento pode ser descrito como:

[...] o produto alimentício produzido pelas abelhas melíferas, a partir do néctar das flores ou das secreções procedentes de partes vivas das plantas ou de excreções de insetos sugadores de plantas que ficam sobre partes vivas de plantas, que as abelhas recolhem, transformam, combinam com substâncias específicas próprias, armazenam e deixam maturar nos favos da colmeia ${ }^{2}$.
Outra definição o apresenta como "a substância viscosa, aromática e açucarada obtida a partir do néctar das flores e ou exsudados sacarínicos que as abelhas melíferas produzem"', sendo esta definição muito similar à utilizada em termos de VISA, que descreve o mel simplesmente como "produto natural elaborado por abelhas a partir de néctar de flores e/ou exsudatos sacarínicos de plantas" 4 . Em termos de Farmacognosia, o mel é um material que pode ser definido como:

[...] um produto natural fornecido pela abelha Apis mellifera L., Apidae, sendo uma solução aquosa concentrada de açúcares, geralmente com predominância de frutose e glucose e ainda com pequenas quantidades de dextrinas, enzimas, ceras, óleos voláteis, ácidos orgânicos, éteres, substâncias gomosas, albuminosas e minerais ${ }^{5}$.

O mel é utilizado pelo homem como alimento desde a pré-história, tendo sido obtido de forma extrativista e predatória levando a danos ambientais e à própria morte do fornecedor do produto, as abelhas melíferas. Com o tempo porém, o homem desenvolveu formas de manejar as abelhas e a produção de mel, o que levou ao desenvolvimento da apicultura ${ }^{3}$.

O emprego do mel como alimento pode ser considerado amplo pois, além de ser consumido puro, está presente como ingrediente em diversos outros alimentos, industrializados ou não, podendo ser encontrado em produtos de panificação, confeitaria, cereais matinais, marmeladas e geleias, produtos lácteos, sorvetes e bebidas não alcoólicas e, em muitas culturas, era e ainda é uma importante fonte de açúcares fermentáveis ${ }^{6}$.

Além da sua utilização como alimento, ou mesmo como ingrediente para outros alimentos, o mel também tem sido usado na terapêutica, devido a alguns de seus constituintes, como vitaminas e sais minerais, e a algumas de suas propriedades (Tabela). Muitos artigos tratam de suas aplicações terapêuticas ${ }^{7,8,9,10,11}$.

Apesar de algumas aplicações ou mesmo de algumas propriedades terapêuticas do mel não serem consensuais, vários de seus efeitos fisiológicos já foram cientificamente comprovados e são aceitos pela Organização das Nações Unidas (FAO - Food and Agriculture Organization of the United Nations). Tais efeitos são'

- Fonte de energia: é uma fonte de calorias imediatamente disponíveis, sendo composto principalmente pelos açúcares simples frutose e glicose, que não requerem processos complexos para sua digestão;

- Presença de nutrientes não energéticos: apesar do quantitativo baixo, a alta qualidade e a disponibilidade dos micronutrientes no mel não processado são considerados responsáveis por alguns efeitos fisiológicos;

- Ação reparadora em aplicações tópicas: sob condições controladas, acelera a regeneração em vários tipos de ferimentos, desde queimaduras à cicatrização pós-operatória, obtendo efeito superior à aplicação de sacarose purificada e a 
Tabela. Nutrientes no mel em relação à necessidade humana.

\begin{tabular}{|c|c|c|c|}
\hline Nutriente & Unidade & $\begin{array}{l}\text { Quantidade média } \\
\text { em } 100 \mathrm{~g} \text { de mel }\end{array}$ & $\begin{array}{l}\text { Ingesta diária } \\
\text { recomendada }\end{array}$ \\
\hline Equivalente energético & kcal & 304 & $2.800,00$ \\
\hline \multicolumn{4}{|l|}{ Vitaminas } \\
\hline A & U.I. & - & $5.000,00$ \\
\hline B1 (Tiamina) & $\mathrm{mg}$ & $0,004-0,006$ & 1,5 \\
\hline B2 (Riboflavina) & $\mathrm{mg}$ & $0,002-0,060$ & 1,7 \\
\hline $\begin{array}{l}\text { Ácido Nicotínico } \\
\text { (Niacina) }\end{array}$ & $\mathrm{mg}$ & $0,110-0,360$ & 20 \\
\hline B6 (Piridoxina) & $\mathrm{mg}$ & $0,008-0,320$ & 2 \\
\hline Ácido Pantotênico & $\mathrm{mg}$ & $0,020-0,110$ & 10 \\
\hline Ácido Fólico & $\mathrm{mg}$ & - & 0,4 \\
\hline $\begin{array}{l}\text { B12 } \\
\text { (Cianocobalamina) }\end{array}$ & $\mathrm{mg}$ & - & 6 \\
\hline C (Ácido Ascórbico) & $\mu \mathrm{g}$ & $2,200-2,400$ & 60 \\
\hline$D$ & $\mathrm{mg}$ & - & 400 \\
\hline E (Tocoferol) & U.I. & - & 30 \\
\hline H (Biotina) & U.I. & - & 0,3 \\
\hline \multicolumn{4}{|l|}{ Minerais } \\
\hline Cálcio & $\mathrm{mg}$ & $4,000-30,000$ & $1.000,00$ \\
\hline Cloro & $\mathrm{mg}$ & $2,000-20,000$ & - \\
\hline Cobre & $\mathrm{mg}$ & $0,010-0,100$ & 2 \\
\hline lodo & $\mathrm{mg}$ & - & 0,15 \\
\hline Ferro & $\mathrm{mg}$ & $1,000-3,400$ & 18 \\
\hline Magnésio & $\mathrm{mg}$ & $0,700-13,000$ & 400 \\
\hline Fósforo & $\mathrm{mg}$ & $2,000-60,000$ & $1.000,00$ \\
\hline Potássio & $\mathrm{mg}$ & $10,000-470,000$ & - \\
\hline Sódio & $\mathrm{mg}$ & $0,600-40,000$ & - \\
\hline Zinco & $\mathrm{mg}$ & $0,200-0,500$ & 15 \\
\hline
\end{tabular}

Fonte: Adaptado de Krell ${ }^{6}$.

preparações especiais de polissacarídeos em pó, além de evitar que bandagens e curativos permaneçam aderidas ao ferimento e às novas camadas frágeis de tecido que se formam;

- Atividade antibacteriana: é a propriedade mais facilmente verificável e a mais estudada. Ela ocorre devido à alta concentração de açúcares e à acidez (pH entre 3,5 e 5,0) no mel não processado e à presença de peróxido de hidrogênio no mel diluído - o peróxido de hidrogênio é um subproduto enzimático obtido durante a formação do ácido glicurônico a partir da glicose, sendo que a enzima responsável, a glicose oxidase, permanece inativa no mel à concentração normal ${ }^{12}$.

As evidências para os efeitos listados acima levaram à aprovação de mel para uso médico no tratamento de ferimentos na Austrália em 1999 e de curativos impregnados com mel para uso médico no Reino Unido em 2004. Atualmente existem vários produtos derivados disponíveis para comercialização na Europa, Austrália, Canadá e Estados Unidos, havendo neste último a aprovação da Agência Americana para Alimentos e Medicamentos (FDA - Food and Drug Administration) ${ }^{13,14}$. No Brasil, foram encontrados apenas méis com proposta de uso terapêutico, mas sem referências específicas sobre suas especificações. Tais especificações parecem seguir a Farmacopeia Americana ${ }^{15}$.
O mel é ainda utilizado em formulações cosméticas pois suas propriedades físico-químicas permitem que desempenhe funções farmacotécnicas, atuando como emoliente, umectante, regulador de $\mathrm{pH}$ e, em certo grau, conservante antimicrobiano ${ }^{8}$, além de ser utilizado como veículo, casos em que a formulação, uma solução para uso oral, é chamada melito ${ }^{16}$.

\section{RELEVÂNCIA SOCIOECONÔMICA DO MEL NO BRASIL}

O Brasil é um dos grandes produtores mundiais de mel e está entre os maiores exportadores deste produto. Até 2005, era o $15^{\circ}$ maior produtor, destacando-se até 2007 como o país que mais expandiu suas exportações, tanto em quantidade quanto em valor. Até 2003, apareceu como o $7^{\circ}$ maior exportador ${ }^{17}$. Em 2010, o país alcançou a $11^{\text {a }}$ posição entre produtores mundiais, sendo que nesse ano o Brasil ocupava a $5^{\text {a }}$ colocação entre os exportadores, em quantidade ${ }^{18}$. Já em 2013, houve um novo aumento na exportação, chegando a mais de $16 \mathrm{mil}$ toneladas, garantindo a $7^{\text {a }}$ posição entre os exportadores ${ }^{19}$. Em 2014, um aumento na exportação de 82\% em relação a 2013 levou o Brasil a ocupar a $8^{\text {a }}$ posição entre os maiores exportadores, com pouco mais de 25.300 toneladas ${ }^{20}$. Apesar do bom desempenho nas exportações, o país ocupou melhor posição no ranking mundial em quantidade do que em valor, indicando que menores produtores não têm conseguido melhores preços. Isso aponta para a necessidade de melhorar a qualidade e o valor agregado do produto.

Na Figura 1, são apresentados os dados consolidados disponibilizados pelo Instituto Brasileiro de Geografia e Estatística (IBGE), através do Sistema de Recuperação Automática - Sidra ${ }^{21}$, e pela Secretaria de Comércio Exterior - Secex, através do sistema AliceWeb ${ }^{22}$, todos em relação ao mel natural, única categoria disponibilizada. Esta última fonte aponta volumes pequenos de importação de mel entre 2003 e 2007, sendo 2004 o ano com o maior volume de importação, com cerca de 38 toneladas. A partir de 2008, não há registros de importação de mel. Não foram encontrados dados que fizessem distinção entre diferentes tipos de mel, nem nesta fonte nem nas demais.

A partir dos dados apresentados, é possível verificar que o Brasil é autossuficiente em relação ao mel e é um exportador relevante. Desta forma, a produção deve cumprir além dos requerimentos sanitários internos, os requerimentos sanitários internacionais, para evitar barreiras técnicas e, ainda mais importante, evitar colocar em risco tanto os consumidores brasileiros quanto os consumidores nos países que importam nosso mel.

A produção de mel está presente em todo o país, sendo que, além do extrativismo, também é encontrada a criação de abelhas com a finalidade de exploração comercial. Além dos enxames nativos e de apiários "artesanais", houve também a expansão da produção especializada e das atividades de suporte à apicultura ${ }^{17}$. Em 2006, o Serviço Brasileiro de Apoio às Micro e Pequenas Empresas (Sebrae) estimava que 350 mil pessoas vivessem no Brasil em função da renda da apicultura, havendo representação significativa da agricultura familiar nesta área ${ }^{23}$. 


\section{RESÍDUOS E CONTAMINANTES QUÍMICOS EMERGENTES EM MEL}

A garantia da inocuidade dos alimentos é imprescindível para a proteção da saúde humana. 0 mel, como vários outros produtos de origem animal, está sujeito, em relação aos perigos químicos, tanto à presença de resíduos de substâncias utilizadas na proteção dos enxames, quanto de contaminantes provenientes do meio ambiente, como agrotóxicos, outros contaminantes orgânicos (como, por exemplo, as bifenilas policloradas) e contaminantes inorgânicos (metais).

Apesar da presença de substâncias no mel com potencial impacto na saúde ser real e esperada pelas agências sanitárias, é necessária a atualização constante quanto a quais substâncias devem ou não ser monitoradas. Nos próximos parágrafos são apresentados resíduos e contaminantes usualmente esperados pelas agências sanitárias e também são relacionados exemplos de classes de substâncias relevantes quando se trata de mel, mas que atualmente não são monitoradas, ou sequer discutidas no Brasil, podendo tais resíduos e contaminantes serem considerados "emergentes" por ainda não serem regulamentados adequadamente no Brasil e em diversas partes do mundo.

Bogdanov $^{24}$ classificou de maneira didática resíduos e contaminantes encontrados em produtos de abelhas, esquematizados e detalhados na Figura 2.

Tratando-se das impurezas que podem ocorrer no mel oriundas do ambiente e que podem ser introduzidas na colmeia pelas abelhas, podem ser destacados:
- Contaminantes inorgânicos como chumbo proveniente da queima de combustíveis para motores (em queda) e o cádmio, proveniente da indústria siderúrgica e de catalisadores, sendo que o cádmio pode ser transportado pelas plantas a partir do solo;

- Contaminantes orgânicos como bifenilas policloradas (PCB - polichlorinated biphenyls) empregadas como líquidos isolantes elétricos (ascarel) e compostos poliaromáticos que foram utilizados no passado e ainda estão presentes no ambiente;

- Agrotóxicos, como inseticidas (organoclorados, organofosforados, carbamatos etc.), antimicrobianos, fungicidas e, com incidência relativamente menor, herbicidas.

Em relação aos perigos químicos que podem ocorrer no mel e que podem ser inseridos pelo homem durante o manejo das abelhas, podem ser destacados:

- Acaricidas utilizados para o controle de ácaros como Varroa destructor, que podem ser agentes sintéticos persistentes como Cimiazol, Fluvalinato, Amitraz, Flumetrin e Coumafós, ou substâncias naturais atóxicas como Timol, solução aquosa de Ácido Lático, solução aquosa de Ácido Oxálico e solução aquosa de Ácido Fórmico;

- Antimicrobianos utilizados para a prevenção da cria pútrida americana (american foulbrood - AFB) e da cria pútrida europeia (european foulbrood - EFB), como sulfonamidas, aminoglicosídeos, tetraciclinas, anfenicóis, macrolídeos, betalactâmicos e metabólitos de nifrofuranos;

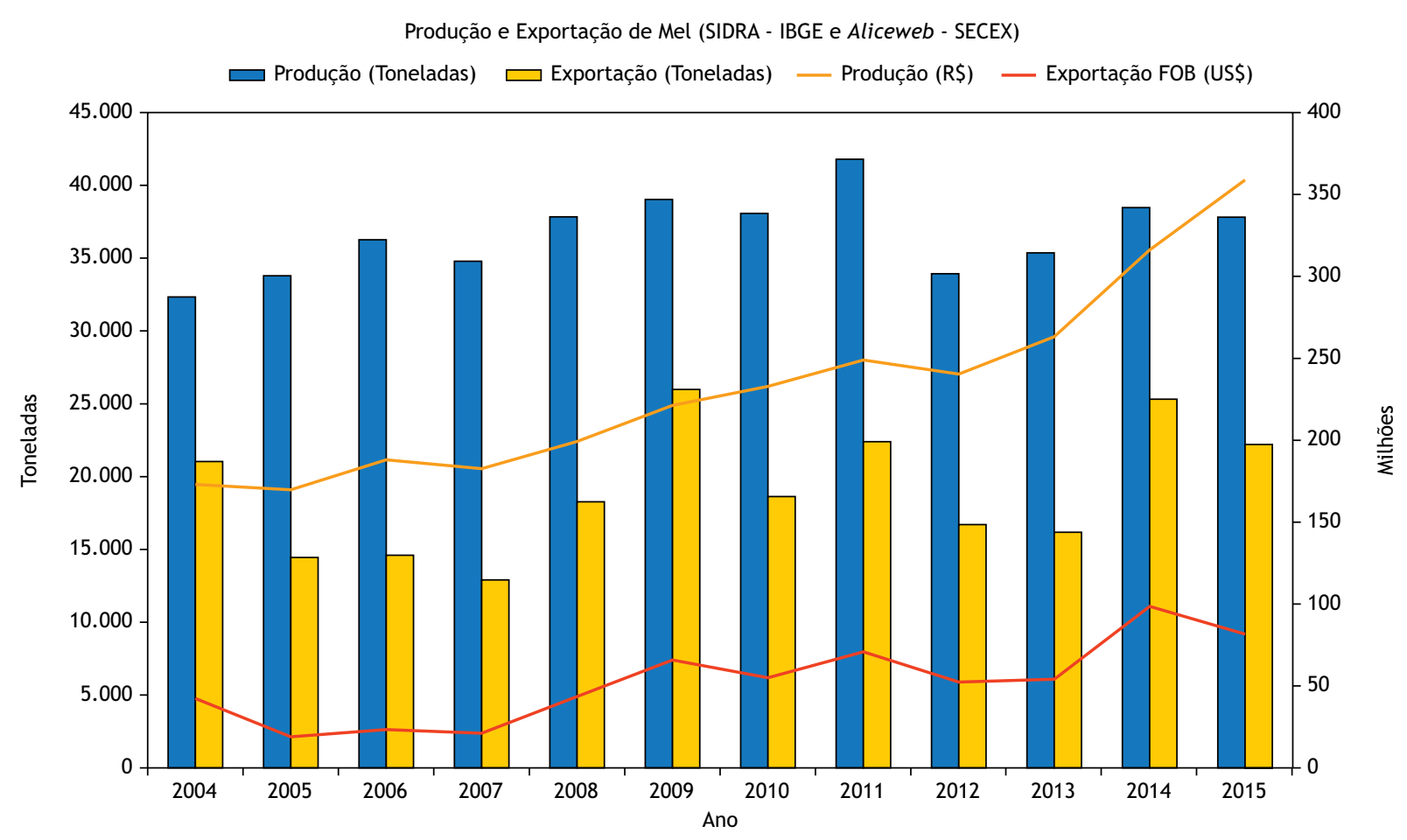

Fonte: Elaboração própria.

Figura 1. Mel: Produção (IBGE) e Exportação (Secretaria de Comércio Exterior - Secex) entre 2004 e 2015. 


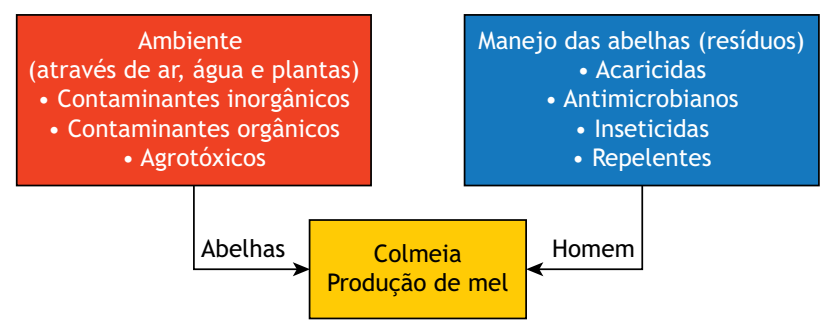

Fonte: Adaptado de Bogdanov²4.

Figura 2. Fontes de perigos químicos para uma colônia de abelhas.

- Inseticidas, como paradiclorobenzeno (PDCB) e naftaleno, para o controle da traça da cera;

- Repelentes como o fenol - entretanto deve haver cautela na avaliação de fenol, uma vez que é um constituinte natural do mel.

Apesar dos diversos agentes que já foram relacionados para uso no manejo das abelhas, a Empresa Brasileira de Pesquisa Agropecuária (Embrapa) desencoraja a utilização de agentes químicos, seja para evitar a resistência microbiana, seja para evitar a ocorrência de resíduos na colmeia. Em nível mundial, entretanto, não é incomum a detecção de resíduos de diversos agentes não autorizados para essa espécie animal, tendo como exemplos detecções realizadas na União Europeia ${ }^{25}$.

$\mathrm{Na}$ categoria de resíduos emergentes, dentre os medicamentos veterinários não autorizados para uso em colmeias, podemos destacar a classe das quinolonas, antimicrobianos associados a quadros de hipersensibilidade ${ }^{26,27}$ e ao desenvolvimento de resistência bacteriana ${ }^{28,29}$. Tais resíduos têm sido encontrados principalmente em méis de origem chinesa, como pode ser verificado no Sistema Rapid Alert System for Food and Feed - Rasff da Comunidade Europeia ${ }^{25}$.

A<smiles>CCN1CCN(c2cc3c(cc2F)c(=O)c(C(=O)O)cn3C2CC2)CC1</smiles>

C<smiles>CCn1cc(C(=O)O)c(=O)c2cc(F)c(N3CCNCC3)cc21</smiles>

As fluoroquinolonas, também conhecidas como quinolonas de segunda geração, foram classificadas pela Organização Mundial de Saúde como uma das quatro classes de antimicrobianos críticos para a saúde humana devido ao risco de seleção para resistência bacteriana, com destaque para Salmonella spp e Escherichia coli em animais. Ao mesmo tempo, as fluoroquinolonas são uma das poucas terapias para infecções graves por Salmonella spp. e E. coli, cuja incidência humana e o número absoluto de ocorrências é alto $^{30}$. Também pela Organização Internacional de Saúde Animal (World Organization for Animal Health - Office International des Epizooties - OIE), essa classe foi considerada como de importância crítica pois possui vasta gama de aplicações terapêuticas e são criticamente importantes no tratamento de septicemias e doenças entéricas e respiratórias ${ }^{31}$. Alguns antimicrobianos representantes da classe são enrofloxacina, ofloxacina, norfloxacina e ciprofloxacina (Figura 3).

Em relação a contaminantes, podem ainda ocorrer no mel substâncias naturais tóxicas, que são metabólitos secundários de plantas utilizadas pelas abelhas na produção de mel. Um dos principais grupos de substâncias nessa situação, que pode ser considerado contaminante emergente, é o grupo dos alcaloides pirrolizidínicos ${ }^{33,34,35}$. Os alcaloides pirrolizidínicos (APs) e seus $\mathrm{N}$-óxidos são produzidos por mais de 6.000 espécies vegetais, incluindo representantes das famílias Boraginaceae, Asteraceae, Fabaceae, Apocynaceae e Orchidaceae e mais de 660 APs já foram isolados. Devido à sua toxicidade aos predadores, como insetos e animais, essas substâncias são também conhecidas como "pesticidas naturais" ${ }^{36}$. Da mesma forma, Prakash e Pereira ${ }^{37}$ apontaram este grupo de alcaloides como o grupo líder dentre as toxinas vegetais associadas a efeitos adversos em humanos e animais. Nesse mesmo trabalho, são discutidas a toxicidade em animais - carcinogenicidade e toxicidade pulmonar - e em humanos - hepatotoxicidade, teratogenicidade e carcinogenicidade - pois tais substâncias, ou seus derivados $\mathrm{N}$-óxidos,

B<smiles>CC1COc2c(N3CCN(C)CC3)c(F)cc3c(=O)c(C(=O)O)cn1c23</smiles>

D<smiles>O=C(O)c1cn(C2CC2)c2cc(N3CCNCC3)c(F)cc2c1=O</smiles>

Fonte: Adaptado de Royal Society of Chemistry ${ }^{32}$.

Figura 3. Enrofloxacina (a), Ofloxacina (b), Norfloxacina (c) e Ciprofloxacina (d). 
parecem reagir prontamente com constituintes celulares nucleofílicos, como o DNA. A Agência Internacional de Pesquisa em Câncer (International Agency for Research on Cancer - IARC) da Organização das Nações Unidas (World Health Organization - WHO) já avaliou diversos APs e classificou três - lasiocarpina, monocrotalina e ridelina - como possivelmente carcinogênicos a humanos (grupo $2 \mathrm{~B}$ ) $38,39,40$. Os núcleos pirrolizidínicos, geralmente a necina ou a otonecina, e alguns exemplos de alcaloides pirrolizidínicos podem ser vistos na Figura 4.

Alguns autores brasileiros relataram a toxicidade dos alcaloides pirrolizidínicos, principalmente em animais ${ }^{41,42}$, mas só foi encontrado até o momento um artigo, bastante recente, sobre a presença desta classe de substâncias em mel no país ${ }^{43}$. Os autores deste artigo desenvolveram e validaram uma metodologia analítica que foi aplicada a 92 amostras de mel. Noventa e nove porcento das amostras revelaram a presença de pelo menos três alcaloides dos oito pesquisados. Em relação às quinolonas não foram identificados manuscritos descrevendo a identificação por pesquisadores brasileiros em méis nacionais. Entretanto, há diversos trabalhos que tratam da resistência microbiana a esta classe de substâncias ${ }^{44,45,46,47}$.

Quando uma busca em âmbito internacional é realizada, percebe-se um cenário diferente. Além dos artigos já citados que tratam dos riscos sanitários relacionados a alcaloides pirrolizidínicos e a quinolonas, também é possível encontrar vários artigos tratando de algumas estratégias analíticas abordando mel tanto para alcaloides pirrolizidínicos ${ }^{48,49,50}$ quanto para quinolonas ${ }^{51,52,53}$. Este fato, por si só, mostra a necessidade de desenvolvimento do conhecimento científico sobre estes contaminantes no Brasil.

Quando trata-se de substâncias naturais tóxicas em mel, talvez a classe dos alcaloides pirrolizidínicos seja a classe mais tóxica relatada, mas não é a única. Dentre as diversas outras classes de
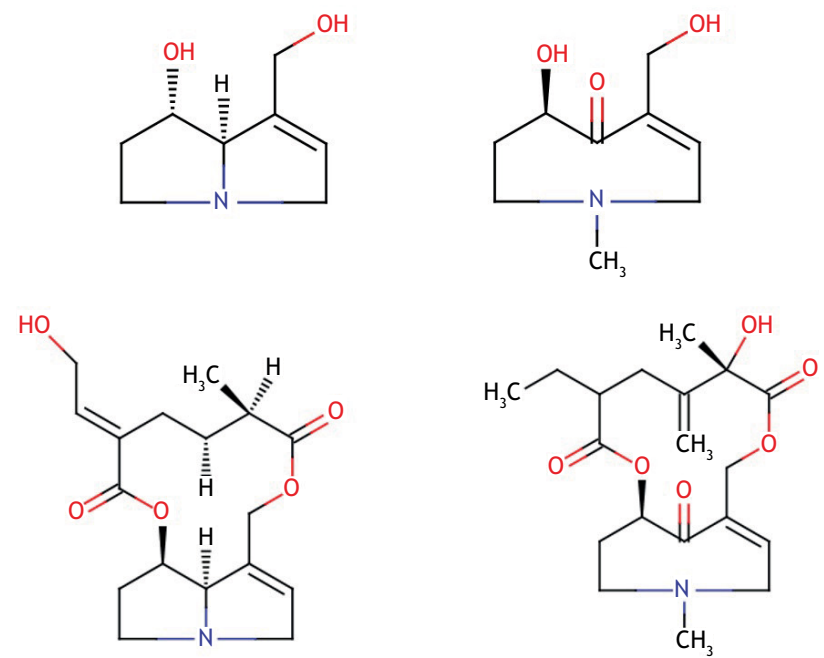

Fonte: Adaptado de Royal Society of Chemistry ${ }^{32}$.

Figura 4. Necina (acima e à esquerda), Otonecina (acima e à direita), Eruciflorina (abaixo e à esquerda) e Emilina (abaixo e à direita). fitotoxinas que podem estar presentes no mel e levar a efeitos tóxicos ${ }^{54}$, é possível destacar a classe das Graianotoxinas, diterpenos com esqueleto tetracíclico A-nor-B-homo-ent-kaurano (Figura 5), produzidos como metabólitos secundários pelos gêneros Rhododendron, Pieris (Andromeda), Leucothoe, Craibiodendron, Lyonia ou Kalmia ${ }^{55}$.

Dentre os efeitos tóxicos das graianotoxinas em humanos estão náusea, hipotensão, bradicardia e comprometimento da consciência ${ }^{56,57,58}$. Graianotoxinas podem estar presentes em méis produzidos em áreas onde os gêneros citados estão presentes e florescem, e sua ingestão pode levar aos efeitos tóxicos descritos ${ }^{55}$.

Mais recentemente uma categoria de contaminantes usualmente abordada para outros alimentos foi também avaliada em mel, os migrantes orgânicos provenientes de embalagens. Lo Turco e colaboradores realizaram um estudo no qual foi investigada a presença de 26 substâncias utilizadas na produção de polímeros plásticos, além de bisfenol $\mathrm{A}$, em amostras de mel de diversas floradas provenientes da Sicília e da Calábria, na Itália e, apesar de não constatarem a presença de bisfenol $\mathrm{A}$, encontraram resíduos de diversos ftalatos ${ }^{59}$.

\section{VIGILÂNCIA SANITÁRIA DE PRODUTOS DE ORIGEM ANIMAL: A SITUAÇÃO DO MEL}

As políticas públicas ligadas a questões de inocuidade alimentar estão sob a égide de diferentes agentes envolvidos nos sistemas regulatórios, e a VISA ocupa seu papel neste cenário como definido pela Lei $n^{\circ} 9.782 / 99$. Essa mesma lei estabelece, além do controle de alimentos, o controle de medicamentos e cosméticos como atribuição da VISA, cujas ações destinam-se a controlar os riscos e danos à saúde da população a fim de proteger, prevenir e controlar doenças e promover a saúde ${ }^{60}$.

Apesar do mel ser utilizado como alimento e ingrediente em alimentos, em formulações farmacêuticas e cosméticas, a legislação sanitária, ou mesmo a legislação de maneira mais ampla, é escassa no país. A legislação brasileira ${ }^{2,3,4}$ trata apenas das definições, parâmetros de rotulagem e especificações físico-químicas, sendo a classificação adotada pela Agência Nacional de Vigilância Sanitária (Anvisa) restrita ao mel de mesa, que atende a todas as especificações definidas para esta classe, e ao mel industrial, que

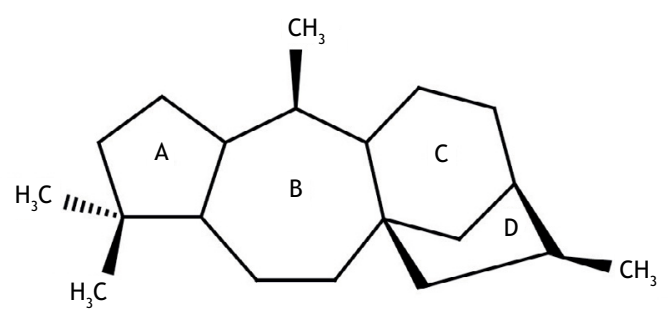

Fonte: Adaptado de These e Bodi ${ }^{55}$.

Figura 5. Esqueleto básico de diversas graianotoxinas. 
deixa de atender a pelo menos uma especificação do mel de mesa, sem deixar de atender às especificações para mel industrial. A Farmacopeia Brasileira ${ }^{61}$ não traz uma monografia sobre o mel e nem mesmo a Farmacopeia Homeopática Brasileira ${ }^{62}$ faz menção ao mel. Esta última fica restrita ao uso apenas das abelhas (uso do animal íntegro) em formulações, sendo este um dos casos em que espécies animais, e não vegetais, são utilizadas como matéria-prima para a produção de medicamentos homeopáticos.

As Farmacopeias Europeia ${ }^{63}$ e Japonesa ${ }^{64}$ contêm monografias para o mel, com especificações físico-químicas semelhantes ao que é encontrado nas legislações nacionais e internacionais. A Farmacopeia Americana ${ }^{15}$ contém uma monografia para mel purificado na qual, além de especificações físico-químicas, há parâmetros microbiológicos para contagem total (1.000 UFC para bactérias e 100 UFC para bolores e leveduras) e ausência de micro-organismos patogênicos, com destaque para a ausência de espécies de Clostridium.

O Codex Alimentarius, apesar de possuir padrão de qualidade definido para mel ${ }^{65}$, faz considerações gerais em relação a resíduos e contaminantes nessa matriz, sendo que, quando buscam-se mais informações sobre níveis aceitáveis ${ }^{66,67}$, vê-se que ainda não foram estabelecidos limites máximos ou tolerâncias.

O comitê de especialistas Joint Expert Commitee on Food Additives (JECFA) ainda não definiu limites máximos de resíduos (LMR) ou de ingestão diária aceitável (IDA) tratando-se do mel ${ }^{68}$. A Comunidade Europeia também não estabeleceu LMR para substâncias em mel ${ }^{69}$, mas tem estabelecido valores de concentração recomendáveis para o desenvolvimento de métodos analíticos para substâncias que ainda não tenham seus limites máximos de resíduos estabelecidos ${ }^{70}$, mas dadas as poucas substâncias, considera-se que o escopo ainda é menos abrangente do que o desejável.

Especificamente sobre os alcaloides pirrolizidínicos é importante ressaltar que a legislação específica ainda é incipiente mundialmente. Michel e Raezke ${ }^{36}$ comentaram sobre a situação atual em diversos países:

- Alemanha: restringe a exposição oral a APs e seus $\mathrm{N}$-óxidos em produtos farmacêuticos derivados de ervas a $1 \mu \mathrm{g} /$ dia por no máximo seis semanas ao ano;

- Austrália e Nova Zelândia: limite provisório de ingestão diária de $1 \mu \mathrm{g} / \mathrm{kg}$ de massa corpórea por dia;

- União Europeia: nível de exposição máxima de $4 \mu \mathrm{g} / \mathrm{kg}$ para óleo de echium;

- Holanda: recomendação de limite de 0,1 $\mu \mathrm{g} / 100 \mathrm{~g}$ de alimentos.

Os mesmos autores recomendaram que mais dados quanto à presença de alcaloides pirrolizidínicos sejam coletados tanto pela indústria quando por laboratórios analíticos.

A mesma situação, de legislação incipiente ou inexistente, é observada em relação à presença em mel de outras fitotoxinas, como as graianotoxinas ${ }^{54}$.
No Brasil existem pelo menos dois programas de destaque no monitoramento de contaminantes e resíduos que têm em seu escopo, dentre outros alimentos, o mel: o Programa Nacional de Controle de Resíduos de Medicamentos Veterinários em Alimentos Expostos ao Consumo (PAMVet) e o Plano Nacional de Controle de Resíduos e Contaminantes (PNCRC).

O PAMVet é conduzido pela Anvisa e tem por objetivo avaliar o potencial de exposição do consumidor a resíduos de medicamentos veterinários pela ingestão de alimentos de origem animal adquiridos no comércio ${ }^{71}$. Apesar do mel estar no escopo, seu monitoramento até o momento não foi implementado de acordo com o cronograma do programa.

O PNCRC é conduzido pelo Ministério da Agricultura, Pecuária e Abastecimento (MAPA) e tem por objetivos verificar e avaliar as boas práticas ao longo de toda a cadeia produtiva, verificar os fatores de qualidade e de segurança higiênicossanitária dos produtos de origem vegetal e animal, seus subprodutos e derivados de valor econômico e importados e fornecer garantia de um sistema seguro e inócuo para disponibilização aos consumidores de modo equivalente àqueles dos requisitos sanitários internacionais ${ }^{72}$. O PNCRC é subdivido em PNCRC/Vegetal e PNCRC/Animal, e o Programa de Controle de Resíduos em Mel (PCRM) está incluído nesse último. Suas diretrizes e planos de trabalho constam na legislação do $\mathrm{PNCRC}^{73}$, sendo que este programa inicialmente monitorou os antimicrobianos tetraciclina, oxitetraciclina, clortetraciclina, sulfatiazol, sulfametazina, sulfadimetoxina e os contaminantes inorgânicos cádmio, chumbo e arsênio. Entretanto, o escopo de monitoramento aumenta a cada ano e, em 2014, estiveram em monitoramento 15 antimicrobianos (entre as classes das tetraciclinas, sulfonamidas, macrolídeos, nitrofuranos e o cloranfenicol), 13 compostos halogenados e organoclorados, três carbamatos, cinco piretróides, oito organofosforados e três contaminantes inorgânicos ${ }^{74}$.

Apesar do esforço brasileiro em relação ao monitoramento de resíduos e contaminantes, deve-se notar que algumas classes de compostos, como as quinolonas, ainda não são abordadas nos programas. Tais antimicrobianos deveriam ser priorizados pois, além de serem relativamente tóxicos, estão diretamente relacionados à capacidade de indução à resistência bacteriana ${ }^{75}$. Também não são abordados nos programas brasileiros os alcaloides pirrolizidínicos, nem as graianotoxinas cujas as respectivas relevâncias, estão relacionadas às suas toxicidades, conforme já discutido. Considerando que é competência da Anvisa o estabelecimento de limites de resíduos e contaminantes para os alimentos de origem animal, é fundamental compreender o risco de exposição do consumidor às substâncias citadas neste artigo de forma que se possa subsidiar as decisões quanto ao gerenciamento desse risco a fim de minimizá-lo ou eliminá-lo.

Em relação à presença de resíduos de substâncias utilizadas na produção de polímeros plásticos, o tema é tratado pela Anvisa e possui histórico de revisão e atualização da legislação, estando em vigência a RDC $n^{\circ} 56$ de 16 de novembro de $2012^{76}$. Esta RDC dispõe sobre a lista positiva de monômeros, outras substâncias 
iniciadoras e polímeros autorizados para a elaboração de embalagens e equipamentos plásticos em contato com alimentos, além de trazer os Limites de Migração Específica (LME) para as diversas substâncias listadas. Entretanto, a avaliação de LME de plastificantes também não está contemplada nos programas de monitoramento que abrangem o mel.

\section{CONCLUSÃO}

A pesquisa e o monitoramento de resíduos e contaminantes em mel são de extrema importância, pois tratam simultaneamente das questões de segurança alimentar e da segurança terapêutica de um produto animal de uso medicinal, farmacêutico e cosmético, abrangendo boa parte do escopo da VISA.

Esse monitoramento, atualmente realizado pelo PNCRC e também proposto pelo PAMVet, necessita de constante atualização do seu escopo para atendimento às demandas atuais e às referentes aos contaminantes emergentes.

Atualmente nenhum desses programas prevê o monitoramento de quinolonas ou de fitotoxinas como os alcaloides pirrolizidínicos e as graianotoxinas.
As quinolonas são uma classe de antimicrobianos que além de estar associada a reações de hipersensibilidade, está vinculada à questão da resistência bacteriana, um dos maiores problemas mundiais de saúde pública.

Os alcaloides pirrolizidínicos, as graianotoxinas e outras fitotoxinas são metabólitos secundários de plantas utilizadas pelas abelhas na produção de mel, sendo assim parte integrante da "matéria-prima" utilizada. Essas substâncias já têm sua toxicidade extensivamente discutida na literatura e podem representar de fato um risco sanitário, pois sabe-se da sua ocorrência em mel, além das plantas que os produzem.

Para os contaminantes emergentes aqui tratados, publicações científicas com dados nacionais são escassas ou inexistentes quando se trata de mel, demostrando que há necessidade de produção de conhecimento científico nessa área.

Recomenda-se assim mais estudos acerca da ocorrência de quinolonas, alcaloides pirrolizidínicos, graianotoxinas e substâncias utilizadas na produção de polímeros plásticos em mel no Brasil, a fim de que os potenciais riscos sanitários provenientes do consumo de mel contendo essas substâncias possam ser conhecidos e minimizados ou eliminados, e a saúde humana, protegida.

\section{REFERÊNCIAS}

1. Rother ET. Revisão sistemática $X$ revisão narrativa. Acta Paul Enferm. 2007;20(2):v-vi. https://doi.org/10.1590/S0103-21002007000200001

2. Ministério da Agricultura e Abastecimento (BR). Instrução Normativa $\mathrm{N}^{\circ} 11$, de 20 de outubro de 2000 . [Regulamento Técnico de Identidade e Qualidade do Mel]. Diário Oficial União. 23 out 2000.

3. Embrapa. Sistemas de produção. Produção de mel 2003. Brasília, DF: Embrapa; 2003[acesso 19 abr 2014]. Disponível em: http://sistemasdeproducao.cnptia.embrapa.br/ FontesHTML/Mel/SPMel/index.htm

4. Ministério da Saúde (BR). Resolução No 12, de 24 de julho de 1978. Normas Técnicas Especiais - Mel. Diário Oficial União. 24 jul 1978.

5. Sociedade Brasileira de Farmacognosia. Análise do mel. Curitiba: Sociedade Brasileira de Farmacognosia; 2014[acesso 19 abr 2014]. Disponível em: http://www.sbfgnosia.org.br/Ensino/analise_mel.html

6. Krell R. Value-added Products from beekeeping. Rome: Food and Agriculture Organization of the United Nations; 1996. (FAO Agricultural services bulletin, vol 124).

7. Al-Waili NS, Salom K, Butler G, Al Ghamdi AA. Honey and microbial infections: a review supporting the use of honey for microbial control. J Med Food. 2011;14(10):1079-96. https://doi.org/10.1089/jmf.2010.0161

8. Burlando B, Cornara L. Honey in dermatology and skin care: a review. J Cosmet Dermatol. 2013;12(4):306-13. https://doi.org/10.1111/jocd.12058
9. Erejuwa 00, Sulaiman SA, Wahab MS. Oligosaccharides might contribute to the antidiabetic effect of honey: a review of the literature. Molecules. 2012;17(1):248-66. https://doi.org/10.3390/molecules 17010248

10. Molan PC. Why honey is effective as a medicine. 1. Its use in modern medicine. Bee World. 1999;80(2):80-92. https://doi.org/10.1080/0005772X.1999.11099430

11. Molan PC. Why honey is effective as a medicine. 2. The scientific explanation of its effects. Bee World. 2001;82(1):22-40. https://doi.org/10.1080/0005772X.2001.11099498

12. Bang $L M$, Buntting $C$, Molan P. The effect of dilution on the rate of hydrogen peroxide production in honey and its implications for wound healing. J Altern Complement Med. 2003;9(2):267-73. https://doi.org/10.1089/10755530360623383

13. Apitherapy News. FDA approves honey wound care products. 15 jul 2012[acesso 17 maio 2014]. Disponível em: http://apitherapy.blogspot.com.br/2012/07/fda-approveshoney-wound-care-products.html

14. Walker L. FDA quietly acknowledges medical benefits of honey. 2008 Mar 21[acesso 17 maio 2014]. Disponível em: http://www.naturalnews.com/022872_honey_FDA_ benefits.html

15. U.S. Pharmacopeial Convention. USP 39 NF 34: United States pharmacopeia and national formulary: Supplement 1. Rockville: U.S. Pharmacopeial Convention; 2016.

16. Destruti ABCB. Noções básicas de farmacotécnica. São Paulo: Editora SENAC; 1999. 
17. Buainain AM, Batalha MO, coordenadores. Cadeias produtivas de flores e mel. Ministério da Agricultura, Pecuária e Abastecimento/Instituto Interamericano de Cooperação para a Agricultura; 2007. (Série Agronegócios, vol 9).

18. Gebrim S. Produção de mel cresce $30 \%$ no último ano. Notícias. 2011[acesso 18 maio 2014]. Disponível em: http://www.agricultura.gov.br/animal/noticias/2011/03/ producao-de-mel-cresce-30porcento-no-ultimo-ano

19. Cuba G. Dados de exportações de mel. Inteligência Comercial. 2014[acesso 18 maio 2014. Disponível em: http://www.beebrazil.com/inteligencia_comercial_ abemel_abril.pdf

20. Cuba G. Setor apícola brasileiro em números. Inteligência Comercial. 16 jul 2015[acesso 25 out 2015]. Disponível em: http://brazilletsbee.com.br/inteligencia_comercial_ abemel_junho_2015.pdf

21. Instituto Brasileiro de Geografia e Estatística - IBGE. Sistema IBGE de Recuperação Automática - SIDRA. Rio de Janeiro: Instituto Brasileiro de Geografia e Estatística; 2016[acesso 2 out 2016]. Disponível em: http://www.sidra.ibge.gov.br/

22. Ministério do Desenvolvimento, Indústria e Comércio Exterior (BR). AliceWeb. Brasília, DF: Ministério do Desenvolvimento, Indústria e Comércio Exterior; 2016[acesso 2 out 2016]. Disponível em: http://aliceweb.mdic.gov.br/

23. 0 salto do mel. SEBRAE Agronegócios. 2006(3):10-11.

24. Bogdanov S. Contaminants of bee products. Apidologie. 2006;37(1):1-18. https://doi.org/10.1051/apido:2005043

25. European Commission. RASFF Portal. 2015[acesso 25 out 2015]. Disponível em: https://webgate.ec.europa.eu/rasff-window/portal/

26. Hadimeri H, Almroth G, Cederbrant K, Eneström S, Hultman P, Lindell A. Allergic nephropathy associated with norfloxacin and ciprofloxacin therapy. Report of two cases and review of the literature. Scand J Urol Nephrol. 1997;31(5):481-5. https://doi.org/10.3109/00365599709030647

27. Lobera T, Audícana MT, Alarcón E, Longo N, Navarro B, Muñoz D. Allergy to quinolones: low cross-reactivity to levofloxacin. J Investig Allergol Clin Immunol. 2010;20(7):607-11.

28. Jacoby GA. Mechanisms of resistance to quinolones. Clin Infect Dis. 2005;41(Suppl 2):S120-6. https://doi.org/10.1086/428052

29. Strahilevitz J, Jacoby GA, Hooper DC, Robicsek A. Plasmid-mediated quinolone resistance: a multifaceted threat. Clin Microbiol Rev. 2009;22(4):664-89. https://doi.org/10.1128/CMR.00016-09

30. World Health Organization - WHO. Critically important antimicrobials for human medicine. 3rd rev. Geneva: World Health Organization; 2012.

31. World Organization for Animal Health. OIE list of antimicrobial agents of veterinary importance. Paris: World Organization for Animal Health; 2015.
32. Royal Society of Chemistry. ChemSpider: search and share chemistry. 2015[acesso 11 set 2015]. Disponível em: http:/ /www.chemspider.com/

33. Boppré $M$. The ecological context of pyrrolizidine alkaloids in food, feed and forage: an overview. Food Addit Contam Part A Chem Anal Control Expo Risk Assess. 2011;28(3):260-81. https://doi.org/10.1080/19440049.2011.555085

34. Edgar JA, Colegate SM, Boppré M, Molyneux RJ. Pyrrolizidine alkaloids in food: a spectrum of potential health consequences. Food Addit Contam Part A Chem Anal Control Expo Risk Assess. 2011;28(3):308-24. https://doi.org/10.1080/19440049.2010.547520

35. Kempf $M$, Wittig $M$, Schönfeld K, Cramer L, Schreier P, Beuerle T. Pyrrolizidine alkaloids in food: downstream contamination in the food chain caused by honey and pollen. Food Addit Contam Part A Chem Anal Control Expo Risk Assess. 2011;28(3):325-31. https://doi.org/10.1080/19440049.2010.521771

36. Michel R, Raezke KP. Pyrrolizidine alkaloids in honey: brief overview regarding de occurrence, toxicological effects and risk assessment. Bremen: Intertek Food Services; 2009.

37. Prakash AS, Pereira TN, Reilly PEB, Seawright AA. Pyrrolizidine alkaloids in human diet. Mutat Res. 1999;443(1-2):53-67. https://doi.org/10.1016/S1383-5742(99)00010-1

38. IARC Working Group on the Evaluation of Carcinogenic Risks to Humans. Some traditional herbal medicines, some mycotoxins, naphthalene and styrene. IARC Monogr Eval Carcinog Risks Hum. 2002;82:1-556.

39. Beuerle T, Benford D, Brimer L, Cottrill B, Doerge D, Dusemund $B$ et al. Scientific opinion on pyrrolizidine alkaloids in food and feed: EFSA Panel on Contaminants in the Food Chain (CONTAM). EFSA J. 2011;9(11):2449. https://doi.org/10.2903/j.efsa.2011.2406

40. World Health Organization, International Agency for Research on Cancer. IARC Monographs on the evaluation of carcinogenic risk of chemicals to man. Lyon: International Agency for Research on Cancer, 1976[acesso $13 \mathrm{fev}$ 2017]. Vol. 10: Some naturally occurring substances. 1976. Disponível em: http://monographs.iarc.fr/ENG/ Monographs/vol1-42/mono10.pdf

41. Lucena RB, Rissi DR, Maia LA, Flores MM, Dantas AFM, Nobre VMdT, et al. Intoxicação por alcaloides pirrolizidínicos em ruminantes e equinos no Brasil. Pesq Vet Bras. 2010;30(5):447-52. https: / /doi.org/10.1590/S0100-736X2010000500013

42. Sandini TM, Udo MSB, Spinosa HDS. Senecio brasiliensis e alcaloides pirrolizidínicos: toxicidade em animais e na saúde humana. Biotemas. 2013;26(2):83-92. http://dx.doi.org/10.5007/2175-7925.2013v26n2p83

43. Valese AC, Molognoni L, Ploêncio LAS, Lima FG, Gonzaga LV, Górniak SL et al. A fast and simple LC-ESI-MS/MS method for detecting pyrrolizidine alkaloids in honey with full validation and measurement uncertainty. Food Control. 2016;67:183-91. https://doi.org/10.1016/j.foodcont.2016.02.050 
44. Barros RR, Kegele FCO, Paula GR, Brito MA, Duarte RS. Molecular characterization of the first fluoroquinolone resistant strains of Streptococcus agalactiae isolated in Brazil. Braz J Infect Dis. 2012;16(5):476-8. https://doi.org/10.1016/j.bjid.2012.05.003

45. Ferreira WA, Ferreira CM, Naveca FG, Almeida NC, Vasconcelos WS, Gomes JS et al. Genotyping of two Neisseria gonorrhoeae fluroquinolone-resistant strains in the Brazilian Amazon Region. Mem Inst Oswaldo Cruz. 2011;106(5):629-31. https://doi.org/10.1590/S0074-02762011000500018

46. Ito CAS, Gales AC, Tognim MCB, Munerato P, Dalla Costa LM. Quinolone-resistant Escherichia coli. Braz J Infect Dis. 2008;12(1):5-9. https://doi.org/10.1590/\$1413-86702008000100003

47. Pereira AS, Andrade SS, Monteiro J, Sader HS, Pignatari ACC, Gales AC. Evaluation of the susceptibility profiles, genetic similarity and presence of qnr gene in Escherichia coli resistant to ciprofloxacin isolated in Brazilian hospitals. Braz J Infect Dis. 2007;11(1):40-3. https://doi.org/10.1590/S1413-86702007000100011

48. Betteridge $\mathrm{K}, \mathrm{Cao} \mathrm{Y}$, Colegate SM. Improved method for extraction and LC-MS analysis of pyrrolizidine alkaloids and their $\mathrm{N}$-oxides in honey: application to Echium vulgare honeys. J Agric Food Chem. 2005;53(6):1894-902.

49. Griffin CT, O'Mahony J, Danaher M, Furey A. Liquid chromatography tandem mass spectrometry detection of targeted pyrrolizidine alkaloids in honeys purchased within Ireland. Food Anal Methods. 2015;8(1):18-31. https://doi.org/10.1007/s12161-014-9855-1

50. Martinello M, Cristofoli C, Gallina A, Mutinelli F. Easy and rapid method for the quantitative determination of pyrrolizidine alkaloids in honey by ultra performance liquid chromatography-mass spectrometry: an evaluation in commercial honey. Food Control. 2014;37:146-52. https://doi.org/10.1016/j.foodcont.2013.09.037

51. Beretta G, Artali R, Caneva E, Orlandini S, Centini M, Facino RM. Quinoline alkaloids in honey: further analytical (HPLC-DAD-ESI-MS, multidimensional diffusion-ordered NMR spectroscopy), theoretical and chemometric studies. J Pharm Biomed Anal. 2009;50(3):432-9. https://doi.org/10.1016/j.jpba.2009.05.029

52. Durden DA, Fernandes G. Quantitation of fluoroquinolones in honey using tandem mass spectrometry (LC-MS/MS): nested validation with two mass spectrometers. J AOAC Int. 2010;93(5):1633-55.

53. Mottier P, Hammel YA, Gremaud E, Guy PA. Quantitative high-throughput analysis of 16 (Fluoro)quinolones in honey using automated extraction by turbulent flow chromatography coupled to liquid chromatography-tandem mass Spectrometry. J Agric Food Chem. 2008;56(1):35-43. https://doi.org/10.1021/jf072934d

54. Islam MN, Khalil MI, Islam MA, Gan SH. Toxic compounds in honey. J Appl Toxicol. 2014;34(7):733-42. https://doi.org/10.1002/jat.2952

55. These A, Bodi D, Uecker S, Reimers K, Ronczka S, Preiss-Weigert $A$, et al. A case of human poisoning by grayanotoxins following honey ingestion: elucidation of the toxin profile by mass spectrometry. Food Addit Contam Part A Chem Anal Control Expo Risk Assess. 2015;32(10):1674-84. https://doi.org/10.1080/19440049.2015.1042410

56. Gunduz A, Turedi S, Russell RM, Ayaz FA. Clinical review of grayanotoxin/mad honey poisoning past and present. Clin Toxicol (Phila). 2008;46(5):437-42. https://doi.org/10.1080/15563650701666306

57. Jansen SA, Kleerekooper I, Hofman ZL, Kappen IF, Stary-Weinzinger A, Heyden MA. Grayanotoxin poisoning: 'mad honey disease' and beyond. Cardiovasc Toxicol. 2012;12(3):208-15. https://doi.org/10.1007/s12012-012-9162-2

58. Lampel KA, Al-Khaldi S, Cahill SM, editors. Bad bug book: handbook of foodborne pathogenic microorganisms and natural toxins. Silver Spring: U.S. Food and Drug Administration; 2012.

59. Lo Turco V, Di Bella G, Potortì AG, Tropea A, Casale EK, Fede MR et al. Determination of plasticisers and BPA in Sicilian and Calabrian nectar honeys by selected ion monitoring GC/MS. Food Addit Contam Part A Chem Anal Cotnrol Expo Risk Assess. 2016;33(11):1693-9. https://doi.org/10.1080/19440049.2016.1239030

60. Brasil. Lei $\mathrm{N}^{\circ}$ 9.782, de 26 de janeiro de 1999. Define o Sistema Nacional de Vigilância Sanitária, cria a Agência Nacional de Vigilância Sanitária e dá outras providências. Diário Oficial União. 27 jan 1999.

61. Agência Nacional de Vigilância Sanitária - Anvisa. Farmacopeia brasileira. 5a ed. Brasília, DF: Agência Nacional de Vigilância Sanitária; 2010.

62. Agência Nacional de Vigilância Sanitária - Anvisa. Farmacopeia homepática brasileira. 3a ed. Brasília, DF: Agência Nacional de Vigilância Sanitária; 2011.

63. Council of Europe. European Pharmacopoeia Commission. European pharmacopoeia. Strasbourg: Council Of Europe; 2014.

64. Pharmaceutical and Medical Device Regulatory Science Society of Japan. The Japanese pharmacopoeia: English version. Tokyo: Pharmaceutical and Medical Device Regulatory Science Society of Japan; 2012.

65. Codex Alimentarius Commission. Revised codex standard for honey: Codex Stan 12-1981, Rev 1 (1987), Rev. 2 (2001). Rome: FAO; 2001.

66. Codex Alimentarius Commission. Maximum residue limits for veterinary drugs in foods. Rome: FAO; 2012.

67. Codex Alimentarius Commission. CODEX Online Commodity Categories. Pesticide residues in food and feed. Rome: FAO; 2014.

68. Food and Agriculture Organization of the United Nations, World Health Orgtanization. Evaluation of certain veterinary drug residues in food: seventieth report of the Joint FAO/WHO Expert Committee on Food Additives. Geneva: World Health Organization; 2009. (Technical report series, vol 954).

69. União Européia. UE 37/2010: Regulamento da Comissão relativo a substâncias farmacologicamente activas e respectiva classificação no que respeita aos limites máximos de resíduos nos alimentos de origem animal. Eur-Lex. 2010. 
70. Community Reference Laboratories. CRLs view on state of the art analytical methdos for national residue control plans. Chicago: Community Reference Laboratories; 2007.

71. Agência Nacional de Vigilância Sanitária - Anvisa. Plano Nacional de Análise de resíduos de medicamentos veterinários em alimentos expostos ao consumo - PAMVet Brasília, DF: Agência Nacional de Vigilância Sanitária; 2003.

72. Ministério da Agricultura, Pecuária e Abastecimento (BR). Plano Nacional de Controle de Resíduos e Contaminantes. Brasília, DF; 2014[acesso 25 maio 2014]. Disponível em: http://www.agricultura.gov.br/portal/page/portal/ Internet-MAPA/pagina-inicial/pncrc

73. Ministério da Agricultura e do Abastecimento (BR). Instrução Normativa n 42, de 22 de dezembro de 1999. Alterar o Plano Nacional de Controle de Resíduos em Produtos de Origem Animal -PNCR e os Programas de Controle de Resíduos em Carne - PCRC, Mel - PCRM,
Leite - PCRL e pescado - PCRP. Diário Oficial União. 22 dez 1999; Seção 1:213.

74. Ministério da Agricultura, Pecuária e Abastecimento (BR). Instrução Normativa № 13, de 15 de julho de 2015. Publica o Subprogramas de Monitoramento e Subprograma Expoloratório do Plano Nacional de Controle de Resíduos e Contaminantes. Diário Oficial União. 20 jul 2015;Seção 1:5-12.

75. Asselt ED, Spiegel M, Noordam MY, Pikkemaat MG, Fels-Klerx HJ. Risk ranking of chemical hazards in food: a case study on antibiotics in the Netherlands. Food Res Int. 2013;54(2):1636-42. https://doi.org/10.1016/j.foodres.2013.08.042

76. Agência Nacional de Vigilância Sanitária - Anvisa. Resolução RDC $N^{\circ}$ 56, de 16 de novembro de 2012. Dispõe sobre a lista positiva de monômeros, outras substâncias iniciadoras e polímeros autorizados para a elaboração de embalagens e equipamentos plásticos em contato com alimentos. Diário Oficial União. 21 nov 2012.

\section{Conflito de Interesse}

Os autores informam não haver qualquer potencial conflito de interesse com pares e instituições, políticos ou financeiros deste estudo. 